\title{
Downregulation of a novel long non-coding RNA, LOC389332, is associated with poor prognosis and tumor progression in clear cell renal cell carcinoma
}

\author{
PING JIN ${ }^{1}$, JUAN WANG ${ }^{2}$ and $\mathrm{YU} \mathrm{LIU}^{3}$ \\ Departments of ${ }^{1}$ Pharmacy, ${ }^{2}$ Clinical Laboratory and ${ }^{3}$ Blood Transfusion, \\ Renmin Hospital, Hubei University of Medicine, Shiyan, Hubei 442000, P.R. China
}

Received September 25, 2015; Accepted October 28, 2016

DOI: $10.3892 /$ etm.2017.4080

\begin{abstract}
It has been demonstrated that various long non-coding RNAs (lncRNAs) may have key roles in various types of cancer. Clear cell renal cell carcinoma (ccRCC) is the most common subtype of all RCCs, accounting for $70-80 \%$ of all cases. The present study identified a novel lncRNA and investigated its clinical significance and physiological function in ccRCC. The expression pattern of the novel lncRNA LOC 389332 in 30 ccRCC tissue samples was examined using reverse-transcription quantitative polymerase chain reaction. The results demonstrated that LOC389332 expression was markedly lower in ccRCC tissues compared with that in matched adjacent non-tumor tissues. Of note, downregulation of LOC389332 expression was significantly associated with the tumor American Joint Commission on Cancer stage $(\mathrm{P}=0.001)$, Fuhrman grade $(\mathrm{P}=0.001)$ and lymph node metastasis $(\mathrm{P}<0.001)$. Furthermore, patients with ccRCC with lower levels of LOC389332 expression had a shorter overall survival time than those with higher LOC389332 expression. A gain-of-function study was used to evaluate the biological function of LOC389332 in ccRCC and the results suggested that restoration of LOC389332 expression inhibited the growth and migration of the 786-O and 769-P cell lines. Therefore, the results of the present study demonstrated that LOC389332 is a novel lncRNA involved in ccRCC progression and may be a potential diagnostic and prognostic biomarker. Ectopic overexpression of LOC389332 may represent a therapeutic strategy for ccRCC.
\end{abstract}

Correspondence to: Professor Yu Liu, Department of Blood Transfusion, Renmin Hospital, Hubei University of Medicine, 39 Middle Chaoyang Road, Maojian, Shiyan, Hubei 442000, P.R. China

E-mail: dodosou@163.com

Professor Juan Wang, Department of Clinical Laboratory, Renmin Hospital, Hubei University of Medicine, 39 Middle Chaoyang Road, Maojian, Shiyan, Hubei 442000, P.R. China

E-mail: wangjuan_rmyy@sina.com

Key words: clear cell renal cell carcinoma, LOC389332, downregulation, prognostic biomarker, progression

\section{Introduction}

Renal cell carcinoma ( $\mathrm{RCC}$ ) has the highest mortality rate of all urological malignancies worldwide and accounts for $\sim 65,000$ new cancer cases per year in the United States alone (1). Clear cell (cc) RCC is the most common subtype and accounts for $70-80 \%$ of all RCC cases $(2,3)$. Metastasis and progression are the most common events in ccRCC and $33 \%$ of affected patients are in the terminal stage at the time of diagnosis $(4,5)$. Patients with metastatic ccRCC have a poor prognosis and the number of therapeutic strategies available is limited (6-8). Therefore, further research into the underlying molecular mechanisms of ccRCC metastasis to identify novel diagnostic biomarkers for ccRCC in the early stages is urgently required.

Long non-coding RNAs (lncRNAs) are a newly identified class of non-coding RNAs, with transcripts of $>200$-bp nucleotides that have no protein-coding function (9). It has been demonstrated that lncRNAs may serve a crucial role in various cellular biological processes and human disease $(10,11)$. As microRNAs, lncRNAs may serve a key role in regulating human cancer cell growth, invasion and apoptosis $(12,13)$. Li et al (14) demonstrated that the upregulation of lncRNA urothelial cancer associated (UCA) 1 was correlated with advanced clinical stage and a poor prognosis in patients with esophageal squamous cell carcinoma. In addition, knockdown of UCA1 was observed to inhibit cell growth, migration and invasion (14). The IncRNA HOXA cluster antisense RNA 2 promotes cancer cell proliferation by epigenetically silencing P21/Polo-like kinase 3/DNA damage inducible transcript 3 expression in gastric carcinoma (15). Furthermore, the lncRNA taurine upregulated gene 1 is highly expressed in hepatocellular carcinoma and promotes cell proliferation and apoptosis by epigenetically silencing Krüppel-like factor 2 (16).

LOC389332 is a 723-bp intragenic lncRNA transcribed from chromosome 5 in the human genome (17). Analysis of previous lncRNA expression signatures by microarray showed that LOC389332 was significantly downregulated in ccRCC $(18,19)$; however, its biological functions in ccRCC have remained elusive. The present study was performed to verify the expression pattern of LOC389332 and evaluate the clinical significance of lncRNA LOC389332 in ccRCC. In addition, the impact of LOC389332 on ccRCC cell proliferation and 
migration was assessed in vitro. The present study aimed to identify whether LOC389332 downregulation was associated with poor prognosis and tumor progression in ccRCC, therefore determining whether LOC389332 may be developed as a novel prognostic biomarker and therapeutic target for ccRCC treatment.

\section{Materials and methods}

Patients and specimens. All 30 samples of ccRCC tissues and paired adjacent non-tumor tissues used in the present study were obtained from 30 patients who had undergone radical nephrectomy at the Department of Urology of Renmin Hospital, Hubei University of Medicine (Hubei, China) between January 2009 and February 2011. Patients were selected on the basis of the following inclusion and exclusion criteria: i) Definite pathological diagnosis of ccRCC according to the World Health Organization criteria (20); ii) suitable formalin-fixed, paraffin-embedded tissue specimens; iii) complete clinicopathological data. None of the patients received radiotherapy or chemotherapy prior to radical nephrectomy. Following surgical resection, specimens were immediately immersed in RNAlater ${ }^{\circledR}$ (Qiagen GmbH, Hilden, Germany) for 30 min and then transferred into liquid nitrogen for cryopreservation until use. The clinicopathological features of the patients are presented in Table I. Follow-up of patients was completed in May 2015 and the median observation time was 30 months. All specimens were collected on the basis of their availability for research and following a protocol approved by the Medical Ethics committee of the Renmin Hospital, Hubei University of Medicine (Hubei, China). Written consent was obtained from all patients participating in the study.

Cell culture. Human ccRCC cell lines (786-O, 769-P, CaKi-1 and RLC-310) and a normal immortalized human proximal tubule epithelial cell line $(\mathrm{HK}-2)$ were obtained from the American Type Culture Collection (Manassas, VA, USA). All cells were cultured in RPMI-1640 medium (Thermo Fisher Scientific, Inc., Waltham, MA, USA), supplemented with $10 \%$ fetal bovine serum (Invitrogen; Thermo Fisher Scientific, Inc.) in a $100 \%$ humidified atmosphere of $5 \% \mathrm{CO}_{2} / 95 \%$ air at $37^{\circ} \mathrm{C}$.

RNA extraction and reverse transcription-quantitative polymerase chain reaction $(R T-q P C R)$. Total RNA from 30 cases of fresh ccRCC tissues and cell lines were extracted using TRIzol ${ }^{\circledR}$ reagent (Invitrogen; Thermo Fisher Scientific, Inc.). RNA was detected and quantified using a NanoDrop ${ }^{\mathrm{TM}}$ 2000c spectrophotometer (Thermo Fisher Scientific, Inc., Wilmington, DE, USA). Subsequently, RNA samples were reverse-transcribed into complementary first-strand DNA using a High-Capacity RNA-to-cDNA kit (Thermo Fisher Scientific, Inc.) according to the manufacturer's instructions. The qPCR reaction was then performed on the LightCycler ${ }^{\circledR}$ 480 Real-Time PCR system (Roche Applied Science, Penzberg, Germany) using the SYBR ${ }^{\circledR}$ Select Master Mix (Thermo Fisher Scientific, Inc.) according to the manufacturer's instructions. The reaction conditions for PCR were as follows: $95^{\circ} \mathrm{C}$ for $20 \mathrm{~min}$, followed by 40 cycles of $95^{\circ} \mathrm{C}$ for $10 \mathrm{sec}, 55^{\circ} \mathrm{C}$ for $30 \mathrm{sec}$ and $72^{\circ} \mathrm{C}$ for $30 \mathrm{sec}$. The specific primers for human LOC389332 were as follows: Forward, 5'-GCGCTCGTCGTC
CTCTTCATCG-3' and reverse, 5'-CGTGGCTCAGTCCCA AGCTACACC-3'. The GAPDH gene was used as an internal control, and the primers for GAPDH were: Forward, 5'-GGC ACCACACCTTCTACAATGAG-3' and reverse, 5'-GGATAG CACAGCCTGGATAGCA-3'. All primers were obtained from Invitrogen (Carlsbad, CA, USA). The relative expression levels of LOC389332 in ccRCC tissues and cell lines were analyzed using the $2^{-\Delta \Delta \mathrm{Cq}}$ method (21).

Cell transfection. As reduction in the expression of LOC389332 in ccRCC tissues and cells was observed, a gain-of-function study was performed by inducing the overexpression of LOC389332 to identify its function in the 786-O and 769-P cell lines. An LOC389332 overexpression plasmid (pcDNA3.1-LOC389332) was purchased from Thermo Fisher Scientific, Inc. 786-O and 769-P cells were treated with the indicated amounts of pcDNA3.1-LOC389332 plasmid using Lipofectamine ${ }^{\circledR} 2000$ reagent (Thermo Fisher Scientific, Inc.). The empty vector pcDNA3.1- was used as a negative control.

Cell migration assay. A scratch wound assay was applied to evaluate the ability of 786-O and 769-P cells to migrate in vitro. Cells ( 2x10\%/well) were seeded into 6-well plates and grown to $70 \%$ confluence $\sim 24 \mathrm{~h}$ prior to infection. Following $6 \mathrm{~h}$ of transfection, similar-sized wounds were generated to the cell monolayers using sterile $100-\mu 1$ pipette tips. Following three washes with phosphate-buffered saline to remove cell debris, cells were cultured in the incubator at $37^{\circ} \mathrm{C}$. In each sample, images of the same area were acquired with a Leica DM LB2 microscope digital camera system (Leica Microsystems $\mathrm{GmbH}$, Wetzlar, Germany) at 0 and $12 \mathrm{~h}$ after the wounds were made to determine the amount of wound closure. The data was calculated using the software program MIAS-2000 (Leica Microsystems $\mathrm{GmbH}$ ). This experiment was performed in triplicate and repeated at least three times.

Cell proliferation assay. 786-O and 769-P cell proliferation was assessed using an MTT assay. Transfected cells were seeded onto each well of 96-well plates at a density of $5 \times 10^{3}$ cells per well. Following $0,24,48,72$ and 96 h of transfection, $15 \mu \mathrm{l}$ of MTT ( $5 \mathrm{mg} / \mathrm{ml}$; Sigma-Aldrich, St. Louis, MO, USA) was added to each well and plates were incubated for $4 \mathrm{~h}$ at room temperature. Subsequently, $130 \mu \mathrm{l}$ dimethyl sulfoxide was added to each well and wells were shaken for $10 \mathrm{~min}$ at $37^{\circ} \mathrm{C}$ to solubilize the formazan crystals. The absorbance of 786-O and 769-P cells was measured at $490 \mathrm{~nm}$ using a Bio-Rad model 680 microplate reader (Bio-Rad Laboratories Inc., Hercules, CA, USA). Results from the MTT assay are presented as the mean of at least three independent experiments.

Statistical analysis. Statistical analysis was performed with SPSS 16.0 (SPSS, Inc., Chicago, IL, USA). Values are expressed as the mean \pm standard deviation. To compare LOC389332 expression levels in ccRCC tissues vs. matched tumor normal tissues, a paired Student's t-test. was used. The $\chi^{2}$ test was applied to compare the levels of LOC389332 expression with various clinicopathological parameters. The results of the MTT assay were analyzed using one-way analysis of variance. Overall survival curves were generated using the 
Table I. Association between LOC389332 expression and clinicopathological parameters of patients with ccRCC.

\begin{tabular}{|c|c|c|c|c|}
\hline \multirow[b]{2}{*}{ Clinicopathological parameter } & \multirow[b]{2}{*}{ Number of cases } & \multicolumn{2}{|c|}{ LOC389332 expression } & \multirow[b]{2}{*}{ P-value } \\
\hline & & Low $(\mathrm{n})$ & $\operatorname{High}(\mathrm{n})$ & \\
\hline Gender & & & & 1.000 \\
\hline Male & 15 & 11 & 4 & \\
\hline Female & 15 & 10 & 5 & \\
\hline Age, years & & & & 0.418 \\
\hline$\leq 60$ & 18 & 14 & 4 & \\
\hline$>60$ & 12 & 7 & 5 & \\
\hline Tumor size, $\mathrm{cm}$ & & & & 0.100 \\
\hline$\leq 4$ & 19 & 11 & 8 & \\
\hline$>4$ & 11 & 10 & 1 & \\
\hline Fuhrman grade & & & & 0.001 \\
\hline $\mathrm{T} 1-\mathrm{T} 2$ & 7 & 1 & 6 & \\
\hline T3-T4 & 23 & 20 & 3 & \\
\hline AJCC stage & & & & 0.001 \\
\hline I-II & 9 & 2 & 7 & \\
\hline III-IV & 21 & 19 & 2 & \\
\hline Lymph node metastasis & & & & $<0.001$ \\
\hline Absent & 10 & 1 & 9 & \\
\hline Present & 20 & 20 & 0 & \\
\hline
\end{tabular}

AJCC stage, tumor stage according to the American Joint Commission on Cancer.

$\mathbf{A}$

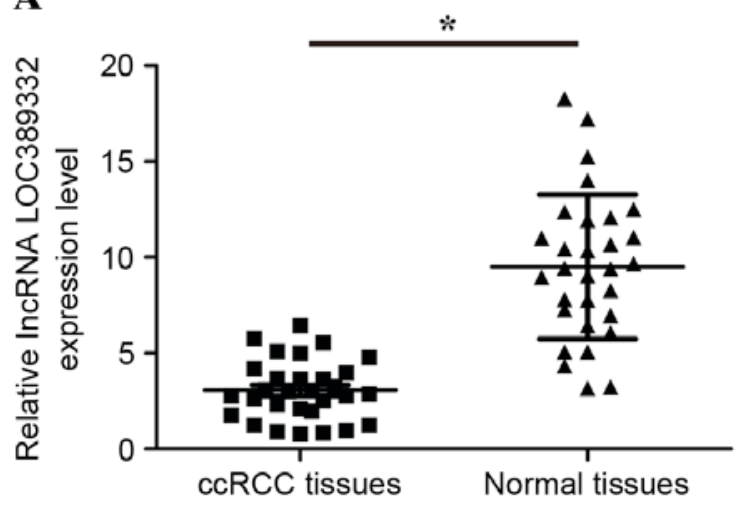

$\mathbf{B}$

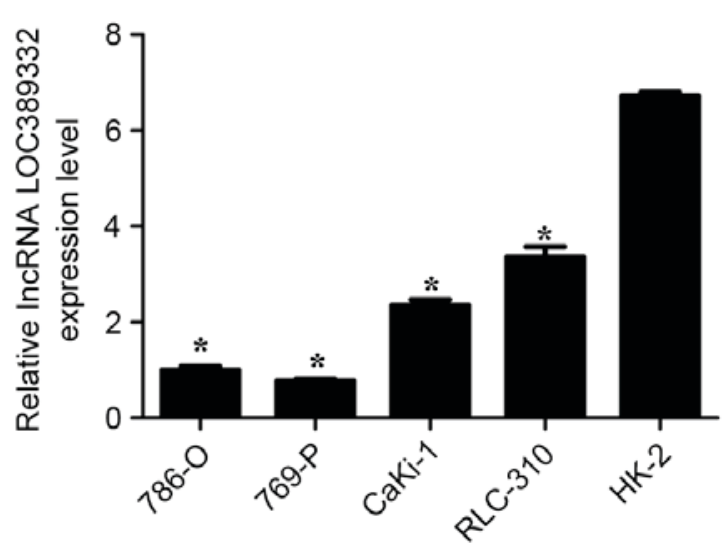

Figure 1. InRNA LOC389332 expression is downregulated in ccRCC tissues and cells. (A) Relative LOC389332 expression was significantly downregulated in ccRCC tissues compared with matched adjacent normal tissues. The bars through the data points indicate the mean \pm standard deviation. (B) Relative LOC389332 expression was significantly lower in ccRCC cell lines than in the normal HK-2 cell line. "P<0.05 vs. HK-2. Data are expressed as the mean \pm standard deviation $(\mathrm{n}=3)$. lncRNA, long non-coding RNA; ccRCC, clear cell renal cell carcinoma.

Kaplan-Meier method. $\mathrm{P}<0.05$ was considered to indicate a statistically significant difference.

\section{Results}

Expression of LOC389332 is downregulated in ccRCC tissues and cells. Previous lncRNA expression profiling of ccRCC indicated that LOC389332 was significantly downregulated in RCC tissues $(18,19)$. To confirm that LOC389332 expression is decreased in ccRCC, RT-qPCR was performed to quantify LOC389332 expression in the $30 \mathrm{ccRCC}$ tissues and ccRCC cell lines. The results demonstrated that LOC389332 expression was significantly lower in ccRCC tissues compared with matched adjacent normal tissues ( $\mathrm{P}<0.05$; Fig. 1A). In addition, LOC389332 expression was significantly downregulated in 786-O, 769-P, CaKi-1 and RLC-310 cell lines, compared with that in the normal HK-2 cell line $(\mathrm{P}<0.05$; Fig. 1B). These results suggested that LOC389332 expression is suppressed in ccRCC. 


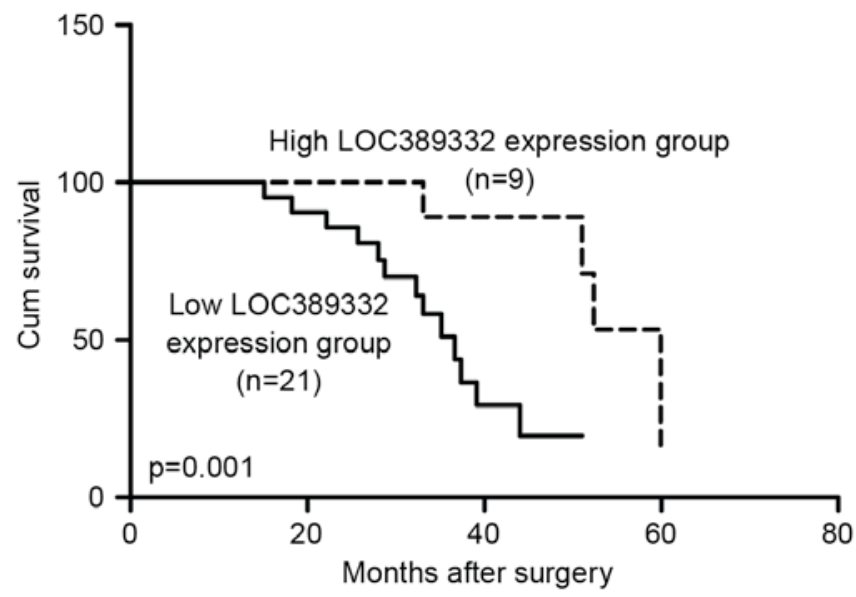

Figure 2. Downregulation of lncRNA LOC389332 predicts poor prognosis in ccRCC patients. Kaplan-Meier survival curves for 30 patients with ccRCC according to high or low levels of LOC389332 expression, defined on the basis of the median value of relative LOC389332 expression. The 3-year survival rate was $72 \%$ in the high LOC389332 group $(\mathrm{n}=9)$ and $54 \%$ in the low LOC389332 group ( $\mathrm{n}=21 ; \mathrm{P}=0.001)$. Cum survival, cumulative survival; lncRNA, long non-coding RNA; ccRCC, clear renal cell carcinoma.

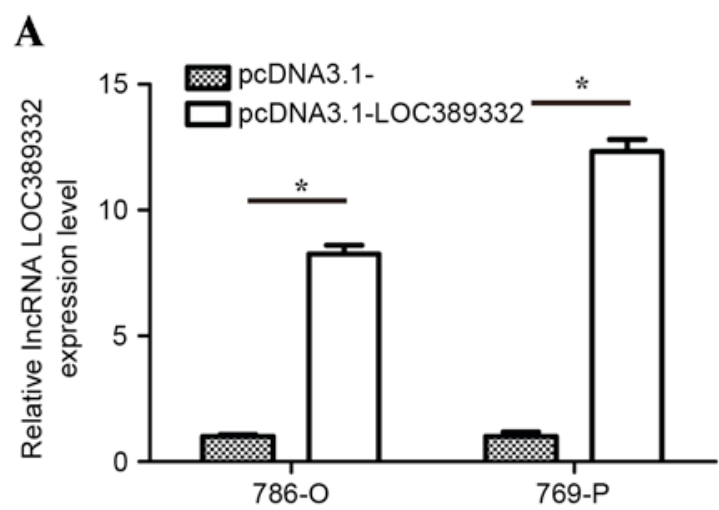

B
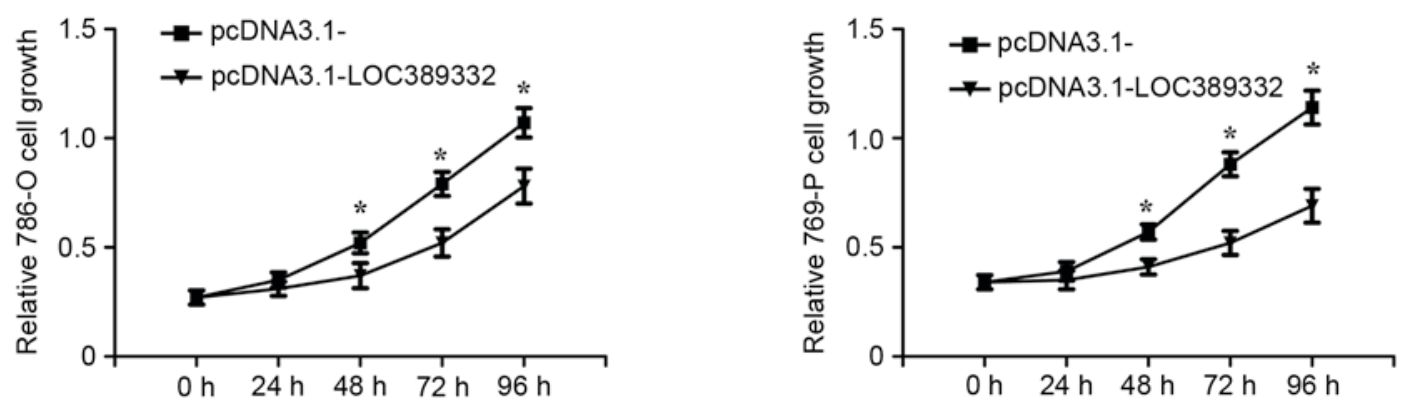

Figure 3. Downregulation of lncRNA LOC389332 inhibits growth of ccRCC cells in vitro. (A) LOC389332 expression in 786-O and 769-P cells following transfection with pcDNA3.1-LOC389332 overexpression plasmid was significantly higher than in those treated with the pcDNA3.1- (empty vector). (B) Proliferation of 786-O and 769-P cells was significantly decreased following treatment with pcDNA3.1-LOC389332 plasmid. Each experiment was independently repeated three times. ${ }^{*} \mathrm{P}<0.05$ vs. pcDNA3.1-LOC389332. IncRNA, long non-coding RNA; ccRCC, clear renal cell carcinoma.

Association between LOC389332 expression and clinicopathological parameters in $c c R C C$. To evaluate the association between LOC389332 expression and the patients' clinicopathological features, the $30 \mathrm{ccRCC}$ samples were divided into low $(n=21)$ and high $(n=9)$ LOC389332 expression groups based on the median value of relative LOC389332 expression. As presented in Table I, downregulation of LOC389332 expression was correlated with tumor American Joint Commission on Cancer (AJCC) stage (22) $(\mathrm{P}=0.001)$, Fuhrman grade (23) $(\mathrm{P}=0.001)$ and lymph node metastasis $(\mathrm{P}<0.001)$. However, no correlation was detected between LOC389332 expression and patient gender $(\mathrm{P}=1.000)$, age $(\mathrm{P}=0.418)$ or tumor size $(\mathrm{P}=0.100)$. These results demonstrated that decreased LOC389332 expression was associated with ccRCC progression and development.

Downregulation of LOC389332 predicts poor prognosis in ccRCC patients. Kaplan-Meier analysis revealed that the overall survival rate of the low LOC389332 expression group was significantly lower than the overall survival of the high LOC389332 expression group ( $\mathrm{P}=0.001$; Fig. 2). The 3-year 
A

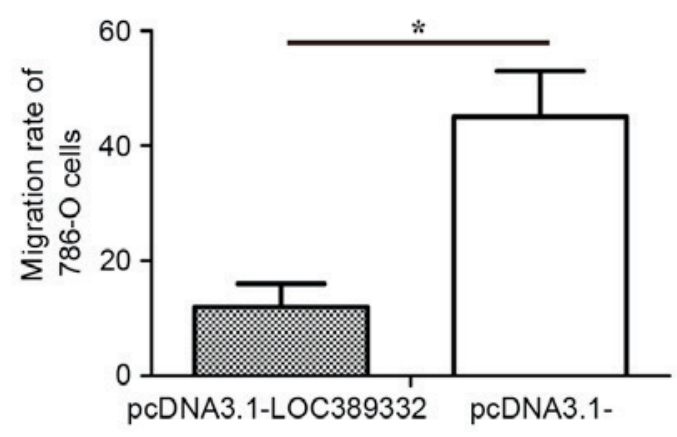

B

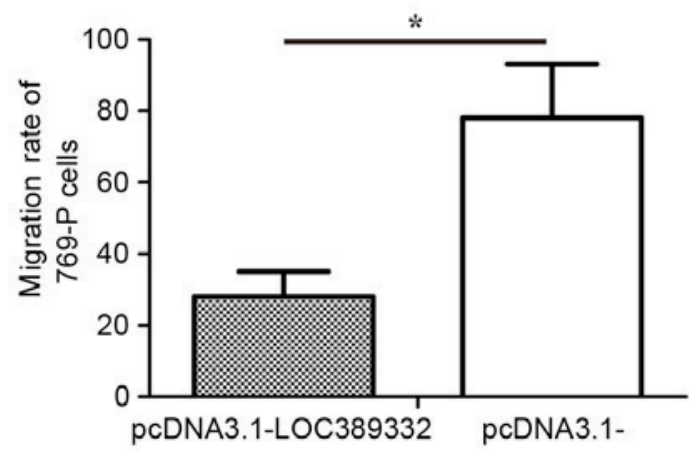

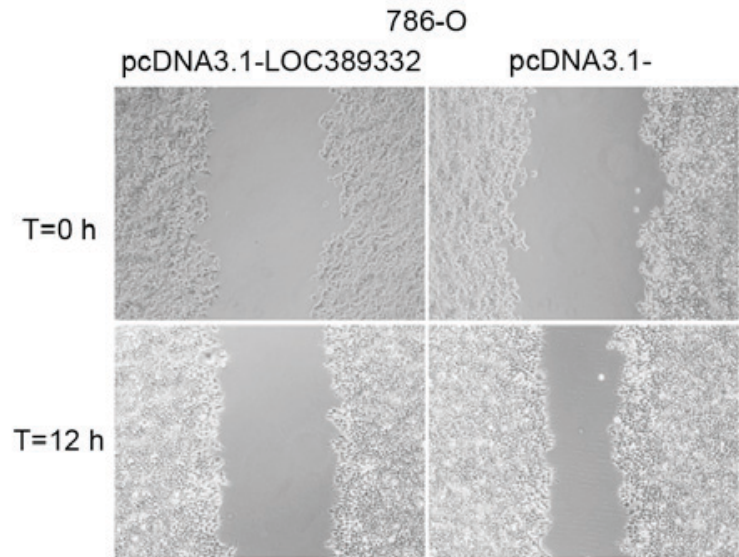

$769-\mathrm{P}$

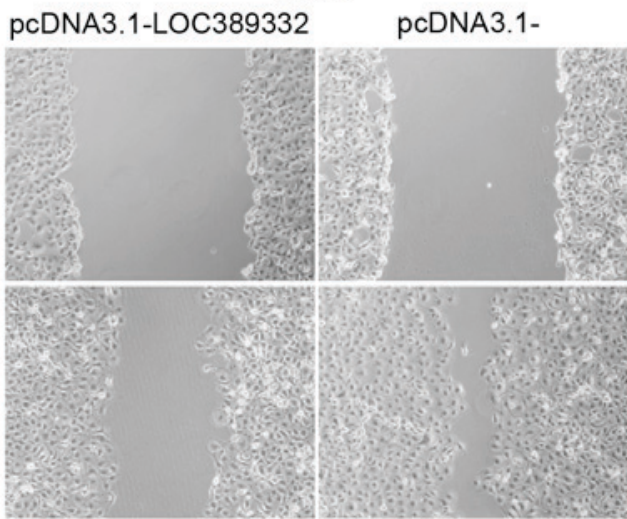

Figure 4. Downregulation of lncRNA LOC389332 inhibits migration of ccRCC cells in vitro. (A) 786-O cells transfected with pcDNA3.1-LOC389332 plasmid or pcDNA3.1-(empty vector), respectively. (B) 769-P cells transfected with pcDNA3.1-LOC389332 plasmid or pcDNA3.1- (empty vector), respectively. All experiments were performed three times and representative images are shown (magnification, $\mathrm{x} 200$ ). ${ }^{*} \mathrm{P}<0.05$. lncRNA, long non-coding RNA, ccRCC, clear cell renal carcinoma.

survival rate for ccRCC patients with low LOC389332 expression was $54 \%$ compared with $83 \%$ in patients with high LOC389332 expression $(\mathrm{P}<0.05)$.

Downregulation of LOC389332 inhibits growth of ccRCC cells in vitro. To identify the biological functions of LOC389332 on ccRCC cells in vitro, transfection of pcDNA3.1-LOC389332 overexpression plasmid were applied to restore LOC389332 expression in 786-O and 769-P cells. RT-qPCR analysis revealed that LOC389332 expression in 786-O and 769-P cells transfected with the pcDNA3.1-LOC389332 plasmid was significantly upregulated compared with that in the pcDNA3.1-empty vector group (Fig. 3A). The MTT assay revealed that the proliferation of the 786-O and 769-P cell lines was significantly decreased in the pcDNA3.1-LOC389332 groups compared with that in the empty vector-transfected groups (Fig. 3B).

Downregulation of LOC389332 inhibits migration of ccRCC cells in vitro. The effect of LOC389332 on ccRCC cell migration was observed using a scratch wound assay. Compared with the pcDNA3.1-empty vector group, overexpression of LOC389332 significantly suppressed the migration capacity of 786-O and 769-P cells ( $\mathrm{P}=0.002$ in each; Fig. 4), suggesting that ectopic overexpression of LOC389332 impairs the migratory capacity of ccRCC cells.

\section{Discussion}

At present, ccRCC has one of the highest mortality rates of all types of kidney disease (24). In spite of improvements in therapeutic strategies for cancer, major challenges still exist regarding the management of patients with ccRCC. Therefore, identifying novel molecular targets to diagnose and treat ccRCC is important to improve the prognosis and clinical outcomes of patients affected.

Over the past few decades, gene expression microarray analysis has been regarded as a useful and promising approach to identify the molecular signatures of ccRCC $(25,26)$. A number of novel lncRNAs have been identified using lncRNA expression profiling and certain altered lncRNA expression patterns have been found to be associated with the genesis and progression of various types of cancer $(27,28)$. It was demonstrated that high expression of the lncRNA metastasis associated lung adenocarcinoma transcript 1 is correlated with tumor progression and poor prognosis in patients with ccRCC (29). Furthermore, upregulation of lncRNA Sprouty RTK signaling antagonist 4-intronic transcript 1 predicts poor prognosis in patients with ccRCC (30). Downregulation of lncRNA growth arrest specific 5 suppresses tumor growth in ccRCC (31). Furthermore, it was demonstrated that decreased expression of neuroblastoma associated transcript 1 
is associated with poor prognosis in patients with ccRCC (32). However, in addition to these few abovementioned lncRNAs, further ones remain to be identified in ccRCC.

Previous studies using lncRNA expression profiling have indicated that IncRNA LOC389332 is significantly downregulated in ccRCC tissue $(18,19)$. However, despite being the most common urological cancer, it remains unknown whether aberrant LOC389332 expression is associated with ccRCC carcinogenesis. The present study investigated the clinical significance of LOC389332 in patients with ccRCC. The RT-qPCR results showed that LOC389332 expression was markedly downregulated in ccRCC tissues and cell lines compared with that in adjacent non-tumor tissues and the normal human proximal tubule epithelial cell line HK-2. In addition, it was demonstrated that LOC389332 expression was strongly associated with the AJCC tumor stage, Fuhrman grade and lymph node metastasis. However, LOC389332 expression was not associated with patient age, gender and tumor size. These results suggested that downregulation of LOC389332 serves an important role in ccRCC progression and development.

The clinicopathological features of patients with ccRCC suggest that LOC389332 may affect the growth and metastasis of ccRCC cells. Therefore, MTT and scratch wound assays were performed to evaluate the biological function of LOC389332 in ccRCC cells. The results demonstrated that ectopic overexpression of LOC389332 significantly inhibits the growth and migratory capacity of 786-O and 769-P cells compared with that of empty vector-transfected cells. This suggested that restoration of LOC389332 expression may inhibit ccRCC development and progression and that high expression of LOC389332 may inhibit malignant phenotypes of ccRCC.

In conclusion, to the best of our knowledge, the present study was the first to identify that the novel lncRNA LOC389332 is downregulated in ccRCC tissues, which is associated with advanced tumor progression. Furthermore, the results suggested that LOC389332 affects ccRCC cell proliferation and migration. Therefore, LOC389332 may be developed as a novel and effective diagnostic and prognostic marker, and ectopic overexpression of LOC389332 may represent a therapeutic strategy for ccRCC.

\section{Acknowledgements}

The present study was supported by the Scientific and Technological Project of Shiyan City of Hubei Province (grant no. ZD2012020).

\section{References}

1. Siegel R, Naishadham D and Jemal A: Cancer statistics, 2013. CA Cancer J Clin 63: 11-30, 2013.

2. Martel CL and Lara PN: Renal cell carcinoma: Current status and future directions. Crit Rev Oncol Hematol 45: 177-190, 2003.

3. Rini BI, Rathmell WK and Godley P: Renal cell carcinoma. Curr Opin Oncol 20: 300-306, 2008.

4. Rini BI, Campbell SC and Escudier B: Renal cell carcinoma. Lancet 373: 1119-1132, 2009.

5. Russo P: Renal cell carcinoma: Presentation, staging, and surgical treatment. Semin Oncol 27: 160-176, 2000.

6. Bhatt JR and Finelli A: Landmarks in the diagnosis and treatment of renal cell carcinoma. Nat Rev Urol 11: 517-525, 2014.

7. Motzer RJ, Bander NH and Nanus DM: Renal-cell carcinoma. N Engl J Med 335: 865-875, 1996.
8. Cho IC and Chung J: Current status of targeted therapy for advanced renal cell carcinoma. Korean J Urol 53: 217-228, 2012.

9. Ponting CP, Oliver PL and Reik W: Evolution and functions of long noncoding RNAs. Cell 136: 629-641, 2009.

10. Esteller M: Non-coding RNAs in human disease. Nat Rev Genet 12: 861-874, 2011.

11. Wapinski $\mathrm{O}$ and Chang HY: Long noncoding RNAs and human disease. Trends Cell Biol 21: 354-361, 2011.

12. Gibb EA, Brown CJ and Lam WL: The functional role of long non-coding RNA in human carcinomas. Mol Cancer 10: 38, 2011.

13. Spizzo R, Almeida MI, Colombatti A and Calin GA: Long non-coding RNAs and cancer: A new frontier of translational research? Oncogene 31: 4577-4587, 2012.

14. Li JY, Ma X and Zhang CB: Overexpression of long non-coding RNA UCA1 predicts a poor prognosis in patients with esophageal squamous cell carcinoma. Int J Clin Exp Pathol 7: 7938-7944, 2014.

15. Xie M, Sun M, Zhu YN, Xia R, Liu YW, Ding J, Ma HW, He XZ, Zhang ZH, Liu ZJ, et al: Long noncoding RNA HOXA-AS2 promotes gastric cancer proliferation by epigenetically silencing P21/PLK3/DDIT3 expression. Oncotarget 6: 33587-33601, 2015.

16. Huang MD, Chen WM, Qi FZ, Sun M, Xu TP, Ma P and Shu YQ: Long non-coding RNA TUG1 is up-regulated in hepatocellular carcinoma and promotes cell growth and apoptosis by epigenetically silencing of KLF2. Mol Cancer 14: 165, 2015.

17. Schmutz J, Martin J, Terry A, Couronne O, Grimwood J, Lowry S, Gordon LA, Scott D, Xie G, Huang W, et al: The DNA sequence and comparative analysis of human chromosome 5. Nature 431: 268-274, 2004.

18. Yu G, Yao W, Wang J, Ma X, Xiao W, Li H, Xia D, Yang Y, Deng K, Xiao H, et al: LncRNAs expression signatures of renal clear cell carcinoma revealed by microarray. PLoS One 7: e42377, 2012

19. Qin C, Han Z, Qian J, Bao M, Li P, Ju X, Zhang S, Zhang L, Li S, Cao Q, et al: Expression pattern of long non-coding RNAs in renal cell carcinoma revealed by microarray. PLoS One 9: e99372, 2014.

20. Lopez-Beltran A, Scarpelli M, Montironi R and Kirkali Z: 2004 WHO classification of the renal tumors of the adults. Eur Urol 49: 798-805, 2006.

21. Schmittgen TD and Livak KJ: Analyzing real-time PCR data by the comparative C(T) method. Nat Protoc 3: 1101-1108, 2008.

22. Edge SB, Byrd DR, Compton CC, Fritz AG, Greene FL and Trotti A (eds): AJCC cancer staging manual. 7th edition. Springer Verlag, New York, NY, pp479-489, 2010.

23. Zimmermann U, Woenckhaus C, Pietschmann S, Junker H, Maile S, Schultz K, Protzel C and Giebel J: Expression of annexin II in conventional renal cell carcinoma is correlated with Fuhrman grade and clinical outcome. Virchows Arch 445: 368-374, 2004.

24. Chow WH and Devesa SS: Contemporary epidemiology of renal cell cancer. Cancer J 14: 288-301, 2008.

25. van Spronsen DJ, de Weijer KJ, Mulders PF and De Mulder PH: Novel treatment strategies in clear-cell metastatic renal cell carcinoma. Anticancer Drugs 16: 709-717, 2005.

26. Takahashi M, Teh BT and Kanayama HO: Elucidation of the molecular signatures of renal cell carcinoma by gene expression profiling. J Med Invest 53: 9-19, 2006.

27. Maruyama R and Suzuki H: Long noncoding RNA involvement in cancer. BMB Rep 45: 604-611, 2012.

28. Lisitsyn NA, Chernyi AA, Karpov VL and Beresten SF: A role of long noncoding RNAs in carcinogenesis. Mol Biol (Mosk) 49: 561-570, 2015 (In Russian).

29. Zhang HM, Yang FQ, Chen SJ, Che J and Zheng JH: Upregulation of long non-coding RNA MALAT1 correlates with tumor progression and poor prognosis in clear cell renal cell carcinoma. Tumour Biol 36: 2947-2955, 2015.

30. Zhang HM, Yang FQ, Yan Y, Che JP and Zheng JH: High expression of long non-coding RNA SPRY4-IT1 predicts poor prognosis of clear cell renal cell carcinoma. Int J Clin Exp Pathol 7: 5801-5809, 2014.

31. Qiao HP, Gao WS, Huo JX and Yang ZS: Long non-coding RNA GAS5 functions as a tumor suppressor in renal cell carcinoma. Asian Pac J Cancer Prev 14: 1077-1082, 2013.

32. Xue S, Li QW, Che JP, Guo Y, Yang FQ and Zheng JH: Decreased expression of long non-coding RNA NBAT-1 is associated with poor prognosis in patients with clear cell renal cell carcinoma. Int J Clin Exp Pathol 8: 3765-3774, 2015. 